\title{
Amine-functionalized nanosilica-supported Dawson heteropolyacid: an eco-friendly and reusable photocatalyst for photodegradation of malachite green
}

\author{
Fatemeh F. Bamoharram • Seyed Heydar Niknezhad • \\ Javad Baharara · Ali Ayati · Mahmood Ebrahimi • \\ Majid M. Heravi
}

Received: 7 January 2014 / Accepted: 10 February 2014/Published online: 9 April 2014

(c) The Author(s) 2014. This article is published with open access at Springerlink.com

\begin{abstract}
Dawson heteropolyacid, $\mathrm{H}_{6}\left[\mathrm{P}_{2} \mathrm{~W}_{18} \mathrm{O}_{62}\right]$, was chemically anchored to the amine-functionalized nanosilica surface in different loadings. The synthesized nanocomposite was characterized by FT-IR spectroscopy and $\mathrm{N}_{2}$ adsorption experiments. The preservation of the structure of the Dawson and dispersion of the cluster on the support were verified on the basis of the spectroscopic data. The photocatalytic degradation efficiency of the synthesized nanocomposites was studied using an aqueous solution of malachite green dye as a model water pollutant. The mineralization of dye contents was investigated in different loadings from 10 to $30 \%$ at room temperature. Decolorization was observed in shorter time using $30 \%$ loading. The photocatalyst was reusable after the filtration and remained active even after being washed with hot water, which confirm its attachment firmly to the surface of amine-functionalized nanosilica.
\end{abstract}

F. F. Bamoharram $(\bowtie) \cdot$ S. H. Niknezhad · M. Ebrahimi

Department of Chemistry, Mashhad Branch,

Islamic Azad University, Mashhad, Iran

e-mail: fbamoharram@mshdiau.ac.ir;

abamoharram@yahoo.com

J. Baharara

Department of Biology, Mashhad Branch,

Islamic Azad University, Mashhad, Iran

\section{A. Ayati}

Laboratory of Green Chemistry, Department of Chemistry, Lappeenranta University of Technology, Sammonkatu 12, 50100 Mikkeli, Finland

M. M. Heravi

Department of Chemistry, Alzahra University, Tehran, Iran
Keywords Heteropolyacid - Dawson - Nanocomposite · Amine-functionalized nanosilica $\cdot$ Photodegradation . Malachit green

\section{Introduction}

Removal of toxic chemicals from the waste waters is one of the most important subjects in pollution control. Many water treatment techniques including condensation, ultrafiltration, membrane separation, and adsorption have been adopted and employed to remove persistent organic compounds and microorganisms from water [1,2].

Among a wide variety of organic water pollutants, malachite green (MG) is one of the most hazardous organic pollutants. It is extensively employed as food coloring agent, food additive, medical disinfectant, and anthelmintic, dye in the silk, wool, jute, leather, cotton, and paper [3]. Unavoidably, in spite of its genotoxic and carcinogenic properties [4], it is still inevitably, being extensively used in the aforementioned industries due to its low cost, availability, and efficacy [5] and from these ways enter massively to the underground waters.

Therefore, it is necessary to develop appropriate treatment methods for entire destruction of these pollutants from the industrial waste water in their sources. Recently, it has been shown that photocatalytic oxidation of organic compounds is an option to conventional and biological methods for the removal of toxic chemicals and other organic pollutants in waste water [6-10]. In this region, several attempts have been carried out on the heterogeneous photocatalysis as an alternative and superior process for the waste water treatment.

In recent years, heteropolyacids (HPAs) have attracted much attention and being used as photocatalysts owing to 
its photophysical and photochemical properties, analogous to semiconductors $[11,12]$.

Considering heterogeneous catalysis, HPAs should be immobilized on a support material and the catalyst should be, preferentially, chemically attached to this support to avoid the leaching during catalytic cycles. HPAs, have been immobilized on solid supports, such as amorphous silica, hexagonal silica or MCM-41 [13-18].Although there are many types of supports, the common silica type is often employed, due to its availability and chemical stability.

There are two common ways that HPAs could be supported on the surface of silica. (a) HPAs are introduced onto the silica via incipient wetness method $[19,20]$. For these materials, leaching of HPAs could also be observed when they were applied to polar solvents. (b) An indirect method in which the silica surfaces are initially functionalized with an amine ligand with subsequent treatment with HPAs [21, 22]. The amine ligand reacted with HPA to obtain salt $\left(\mathrm{NH}_{3} \cdot \mathrm{HPA}\right)$ whose bond is much stronger than the hydrogen bond between silanol group and HPA, thus the HPA was held firmly to the silica surface.

In this paper, in continuation of our interests and experiences on HPAs [23] and cited references therein [23] for extending the applications of Dawson HPA, a novel nanocomposite based on propylamine-functionalized nanosilica and Dawson polyoxometalate, $\mathrm{H}_{6}\left[\mathrm{P}_{2} \mathrm{~W}_{18} \mathrm{O}_{62}\right]$, have been prepared in different loadings and their capability examined for photocatalytic degradation of MG.

\section{Experimental}

\section{Chemicals and instruments}

All chemicals were purchased from commercial sources and used as received. FT-IR spectra were recorded using a Brucker scientific spectrometer (solid sample, $\mathrm{KBr}$ pellets). A double beam UV-Vis spectrophotometer was used for UV-Vis analysis (OPTIZEN 3220). The specific surface area $\left(S_{\mathrm{BET}}\right)$ of supports and catalysts was determined by nitrogen adsorption/desorption technique (ambient temperature: $296^{\circ} \mathrm{K}$, ambient pressure: 0.88 atm, gas flow rate: $10 \mathrm{sccm}$, attenuation: 32 , detector temperature: $\left.70{ }^{\circ} \mathrm{C}\right)$.

\section{Preparation of Dawson acid}

The Dawson acid, $\mathrm{H}_{6}\left[\mathrm{P}_{2} \mathrm{~W}_{18} \mathrm{O}_{62}\right]$, was prepared from a $\alpha / \beta$ $\mathrm{K}_{6} \mathrm{P}_{2} \mathrm{~W}_{18} \mathrm{O}_{62}$ mixture. Orthophosphoric acid in a $4: 1$ acid/ salt ratio was added to a boiling solution of sodium tungstate, and the mixture was refluxed for $8 \mathrm{~h}$. The salt was precipitated by adding potassium chloride, then purified by recrystallization. The product was filtered, washed and then vacuum dried for $8 \mathrm{~h}$. Purity was checked by comparison of IR spectra and results showed that obtained Dawson is pure.

The acid was obtained from an aqueous solution of salt, and treated with ether and concentrated $\mathrm{HCl}$ solution. The ether was evaporated and the remaining solution was placed in a vacuum desiccator until being crystallized.

Preparation of amine-functionalized nanosilicasupported Dawson

For the preparation of amine-functionalized nanosilica, nanosilica was suspended in toluene and refluxed for $1 \mathrm{~h}$. Next, 3-aminopropyltriethoxy silane was added into the above mixture with further stirring for $48 \mathrm{~h}$. The product was obtained by filtration, washed with toluene, ethanol and water, and dried in vacuum for $12 \mathrm{~h}$. Amine-functionalized nanosilica-supported Dawson, was synthesized by impregnating the obtained powder with an aqueous solution of the Dawson in different loadings (10-30\%). After stirring the mixture, the solvent was evaporated to dryness. The obtained powder was dried in an oven at $80-85^{\circ} \mathrm{C}$.

\section{Photocatalytic test}

In a typical reaction, photocatalyst was added to a solution of MG, sonicated for $10 \mathrm{~min}$ and left over for $15 \mathrm{~min}$ in a dark place. The mixture was irradiated under a high-pressure mercury lamp as UV light source at constant temperature of $25^{\circ} \mathrm{C}$. At given irradiation time intervals, liquid samples were taken from the mixture and the absorbance of the malachite green solution was measured using a UV-Vis spectrophotometer.

\section{Results and discussion}

Amine-functionalized nanosilica-supported HPA was obtained via the wet impregnation technique by the addition of HPA to functionalized nanosilica in water. HPA molecules can be immobilized onto nanosilica through the interaction between silica and HPA molecules.

The nanosilica $\mathrm{NH}_{2}$-HPA nanocomposites were resistant to the removal with water due to strong interaction between the HPA and the support.

Loading of HPAs on silica allows heterogenous HPA catalysis with many advantages such as easy separation of the catalyst. This also effectively increases the surface area of HPAs [24]. 
BET calculation based on nitrogen adsorption studies revealed that the specific surface area increased after the immobilization of the Dawson HPA on the functionalized nanosilica support. The BET surface area of HPA, and supported compounds with 10 and $30 \%$ loadings (HPA content covered on the nanosilica, W\%) were obtained as $0.848,2.485$ and $6.192 \mathrm{~m}^{2} / \mathrm{g}$, respectively. Dispersing HPAs on solid supports is important because the surface area of unsupported HPAs is usually low [25]. It was found that the surface area increases as the amount of HPA loading increases. The increase in surface area upon HPA loading may be due to the high dispersion of the HPA on support, providing more surface area and active sites, compared to the unloaded HPA.

FT-IR spectra of functionalized nanosilica-Dawson nanocomposites in the $400-1100 \mathrm{~cm}^{-1}$ region showed the main strong bands due to the silica framework (Fig. 1). For example intense and broad stretching vibrations characteristic for silica framework at ca. 1080, 795 and $467 \mathrm{~cm}^{-1}$ due to $v_{\text {as }}(\mathrm{Si}-\mathrm{O}-\mathrm{Si}), v_{\mathrm{s}}(\mathrm{Si}-\mathrm{O}-\mathrm{Si})$ and $\delta(\mathrm{O}-\mathrm{Si}-\mathrm{O})$ [15] were observed in the spectrum. These bands, together with two shoulders at about 950 and $550 \mathrm{~cm}^{-1}$ for amine-functionalized nanosilica, obscured partially the characteristic bands of Dawson of the stretching vibrations of $\mathrm{P}-\mathrm{O}, \mathrm{W}=\mathrm{O}$ and $\mathrm{W}-$ O-W bonds in 1090, 962, 914 and $773 \mathrm{~cm}^{-1}$, respectively. The aforementioned bands were observed vividly by subtraction of silica $\mathrm{NH}_{2}$-Dawson spectra with the spectrum of amine-functionalized nanosilica. In general, these results indicate that when Dawson is immobilized on the amine functionalized nanosilica support, no degradation of Dawson-type occurs and Dawson interacts with the nanosilica surface and binds to it strongly and firmly.

The photodegradation of the MG in a designed photoreactor was performed to estimate the catalytic activity of the synthesized nanocomposites in different loadings (10-30\%). The intensity changes of UV band in malachite green in a photocatalytic reaction were examined. Figure 2 shows UV-Vis results. It is clear that the photocatalytic activity depends on the percentage of loadings.

Under the effects of UV light, the catalyst was activated by incident light energy which was higher than the energy bands of HPA, leading to the charge transfer from an $\mathrm{O}^{2-}$ ion to a $\mathrm{W}^{6+}$ ion. This charge transfer led to the formation of a pair of hole center $\left(\mathrm{O}^{-}\right)$and trapped electron center $\left(\mathrm{W}^{5+}\right)$ or a strongly oxidizing excited state of HPA. The band gap energy refers to the energy difference between the HOMO and LUMO. The gaps inhibit the recombination of electrons and holes that are generated by the irradiation of the surface of the photocatalyst with the light energy higher than the band gap energy [26]. Photooxidation of the organic compounds was performed via the reaction of the $\mathrm{OH}$ radical or direct reaction of excited HPA catalyst with the substrate. The "surface" bound $\mathrm{OH}$ radicals were produced by the reaction of the excited catalyst with water. The formation of the $\mathrm{OH}$ radical has been confirmed and well established [27]. Finally, reoxidation of the HPA catalyst to its original oxidation state was easily performed using an electron acceptor such as dioxygen. The rate-determining step in the photocatalytic cycle is the reoxidation of the catalyst. The reoxidized form of POM makes the reaction to progress.

From Fig. 2, we can conclude, there is an increase in photocatalytic activity, resulting in $100 \%$ bleaching of the dye after $40 \mathrm{~min}$ in the presence of $30 \%$ loadings. With 10 and $20 \%$ loadings, the bleaching of the dye is obtained after 60 and $65 \mathrm{~min}$. There is no difference between catalytic activity in 10 and $20 \%$ loadings. It is attributed to the partial degradation of heteropolyacid on the support in low loadings. The decomposition of Dawson ions on the $\mathrm{SiO}_{2}$ support at low loadings is due to the strong interaction with the silanol groups [28]. As expected when surface area was increased, photocatalytic activity is increased accordingly.

There are three types of catalysis of solid HPAs; surface type, bulk type I, and bulk type II catalysis. Surface-type catalysis is the ordinary heterogeneous catalysis, where the reactions take place on the two-dimensional surface of solid catalysts. The reaction rate is proportional to the surface area in principle. In the bulk-type (I) catalysis, e.g., acid-catalyzed reactions of polar molecules over the hydrogen forms and group A salts at relatively low temperatures, the reactant molecules are absorbed in the interpolyanion space of the ionic crystal and react there, and then the products desorbed from the solid. The solid behaves in a sense like a solution and the reaction field becomes three dimensional. Therefore, it is called "pseudoliquid" catalysis. The reaction rate is proportional to the volume of catalyst or, for example, the rate of acidcatalyzed reaction is governed by the bulk acidity. This type of catalysis has been observed not only for gas-solid but also for liquid-solid systems.

In bulk type II, although the principal reaction may proceed on the surface, the whole solid bulk takes part in redox catalysis owing to the rapid migration of redox carriers such as protons and electrons. The rate is proportional to the volume of catalyst in the ideal bulk-type (II) catalysis.

Because the bleaching time of MG is decreased with increase in surface area, it is suggested that, the photodegradation of malachite green proceeds via a surface type catalysis. At the end of the reaction, the photocatalyst was filtered, washed, dried, and reused in another reaction. The recycled photocatalyst was used in four reactions without observation of appreciable loss in its catalytic activity. It means that the catalyst structure is preserved. 
Fig. 1 IR spectra of a Dawson heteropolyacid, b Aminefunctionalized nanosilica, c Amine-functionalized nanosilica-supported Dawson
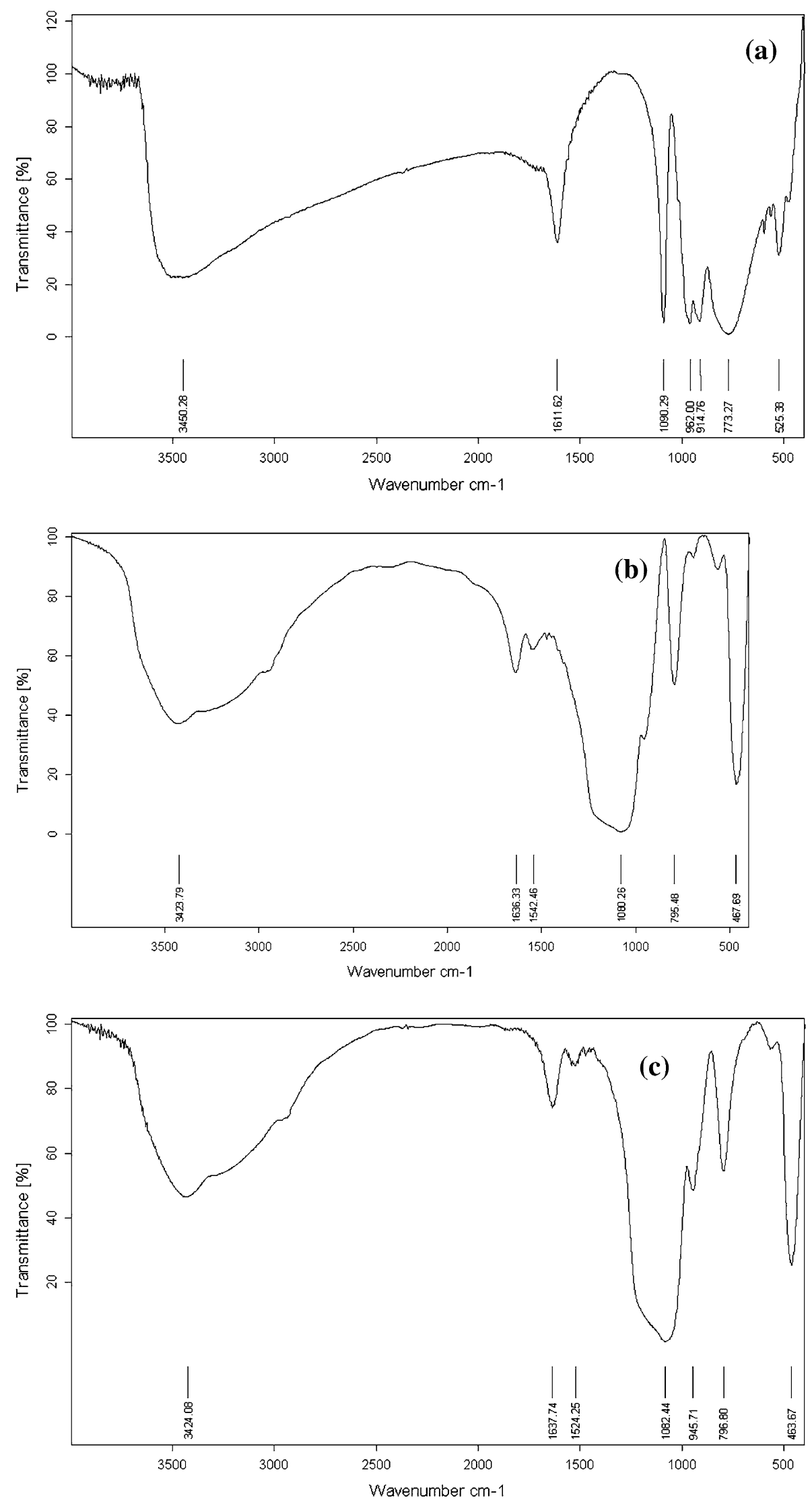
Fig. 2 Photodegradation of MG in different loadings: a $30 \%$, b $20 \%$ and c $10 \%$
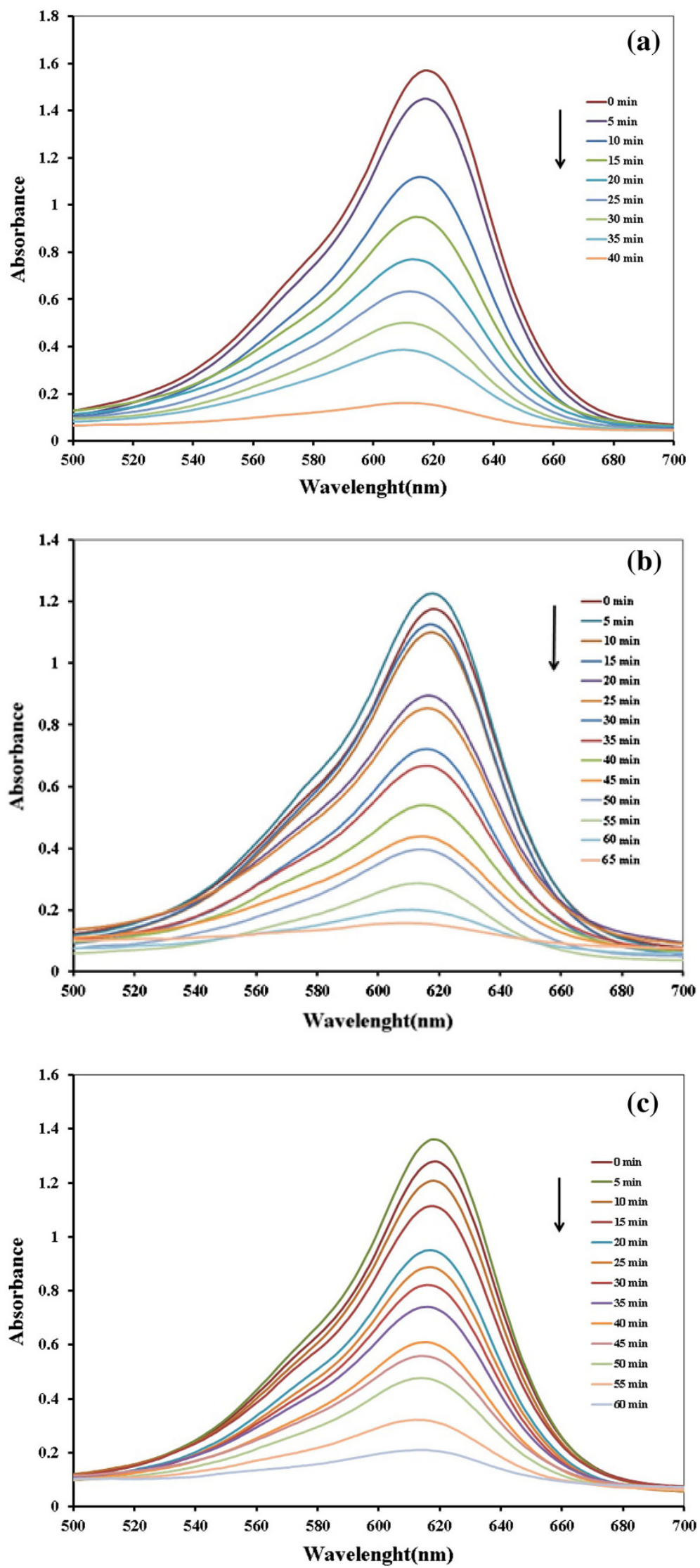


\section{Conclusions}

In conclusion, the present study, demonstrates the photocatalytic activity of amine-functionalized nanosilica-supported Dawson HPA for the photodegradation of MG in heterogeneous conditions. The results showed that the HPA is strongly bounded to the support surface and loading percentage is an important factor. The significance of this study using inexpensive and easily prepared catalysts fundamentally lies in the fact that their applications would lead to an alternative technology for the other systems for removal of toxic chemicals from the waste water, which are of interest for the environmental scientists, and nanotechnologists, along with the advantages from the environmental point of view. In addition, we hope this simple experimental setup and procedure make this method a useful addition to the present methodologies and applications in large-scale chemical activities.

Open Access This article is distributed under the terms of the Creative Commons Attribution License which permits any use, distribution, and reproduction in any medium, provided the original author(s) and the source are credited.

\section{References}

1. Sahinkaya, E., Uzal, N., Yetis, U., Dilek, F.B.: Biological treatment and nanofiltration of denim textile wastewater for reuse. J. Hazard. Mater. 153(3), 1142-1148 (2008)

2. Abe, R.: Recent progress on photocatalytic and photoelectrochemical water splitting under visible light irradiation. J. Photochem. Photobiol. C 11(4), 179-209 (2010)

3. Culp, S.J., Beland, F.A.: Malachite green: a toxicological review. J. Am. Coll. Toxicol. 15, 219-238 (1996)

4. Culp, S.J., Beland, F.A., Heflich, R.H., Benson, R.W., Blankenship, L.R., Webb, P.J., Mellick, P.W., Trotter, R.W., Shelton, S.D., Greenlees, K.J., Manjanatha, M.G.: Mutagenicity and carcinogenicity in relation to DNA adduct formation in rats fed Leuco malachite green. Mutat. Res. 506/507, 55-63 (2002)

5. Schnick, R.A.: The impetus to register new therapeutants for aquaculture. Prog. Fish Cult. 50, 190-196 (1998)

6. Shahmoradi, B., Ibrahim, I.A., Sakamoto, N., Ananda, S., Somashekar, R., Guru Row, T.N., Byrappa, K.: Photocatalytic treatment of municipal wastewater using modified neodymium doped $\mathrm{TiO}_{2}$ hybrid nanoparticles. J. Environ. Sci. Health: Part A 45, 1248-1255 (2010)

7. Byrappa, K., Sunitha, M.H., Subramani, A.K., Ananda, S., Rai, K.M.L., Basavalingu, B., Yoshimura, M.: Hydrothermal preparation of neodymiumoxide coated titania composite designer particulates and its application in the photocatalytic degradation of Procion Red dye. J. Mater. Sci. 41, 1369-1375 (2006)

8. Robert, D., Piscopo, A., Weber, J.V.: First approach of the selective treatment of water by heterogeneous photocatalysis. Environ. Chem. Lett. 2, 5-8 (2004)

9. Zou, S.W., How, C.W., Chen, J.P.: Photocatalytic treatment of waste water contaminated with organic waste and copper ions from the semiconductor industry. Ind. J. Eng. Chem. Res. 46, 6566-6571 (2007)
10. Li, X.Z., Liu, H., Cheng, L.F., Tong, H.J.: Photocatalytic oxidation using new catalyst $\mathrm{TiO}_{2}$ microsphere for water and wastewater treatment. J. Environ. Sci. Technol. 37, 3989-3994 (2003)

11. Salavati, H., Tavakkoli, N., Hosseinpoor, M.: Preparation and characterization of polyphosphotungstate $/ \mathrm{ZrO}_{2}$ nanocomposite and their sonocatalytic and photocatalytic activity under UV light illumination. Ultrason. Sonochem. 19, 546-553 (2012)

12. Sui, C., Li, C., Guo, X.: Facile synthesis of silver nanoparticlesmodified $\mathrm{PVA} / \mathrm{H}_{4} \mathrm{SiW}_{12} \mathrm{O}_{40}$ nanofibers-based electrospinning to enhance photocatalytic activity. Appl. Surface Sci. 258, 7105-7111 (2012)

13. Izumi, Y., Hasebe, R., Urabe, K.: Catalysis by heterogeneous supported heteropoly acid. J. Catal. 84, 402-409 (1983)

14. Marme, F., Coudurier, G., Ve'drine, J.: Acid-type catalytic properties of heteropolyacid $\mathrm{H}_{3} \mathrm{PW}_{12} \mathrm{O}_{40}$ supported on various porous silica-based materials. Micropor. Mesopor. Mater. 22(1-3), 151-163 (1998)

15. Kozhevnikov, I.V., Kloetstra, K.R., Sinnema, A., Zandbergen, H.W., Bekkum, H.: The study of catalysts comprising heteropoly acid $\mathrm{H}_{3} \mathrm{PW}_{12} \mathrm{O}_{40}$ supported on MCM-41 molecular sieve and amorphous silica. J. Mol. Catal. A. 114, 287-298 (1996)

16. Ghanbari-Siahkali, A., Philippou, J., Dwyer, M.W.: The acidity and catalytic activity of heteropoly acid on MCM-41 investigated by MAS NMR, FTIR and catalytic tests. Appl. Catal. A: Gen. 192, 57-69 (2000)

17. Molna'r, A., Keresszegi, C., Torok, B.: Heteropoly acids immobilized into a silica matrix: characterization and catalytic applications. Appl. Catal. A: Gen. 189(2), 217-224 (1999)

18. Damyanova, S., Dimitrov, L., Mariscal, R., Fierro, J.L.G., Petrov, L., Sobrados, I.: Immobilization of 12-molybdophosphoric and 12-tungtophosphoric acids on metal-substituted hexagonal mesoporous silica. Appl. Catal. A: Gen. 256, 183-197 (2003)

19. Xia, Q.H., Hidajat, K., Kawi, S.: Structure, acidity, and catalytic activity of mesoporous acid catalysts for the gas-phase synthesis of MTBE from MeOH and ButOH. J. Catal. 209, 433-444 (2002)

20. Wang, J., Zhu, H.O.: Alkylation of 1-dodecene with benzene over $\mathrm{H}_{3} \mathrm{PW}_{12} \mathrm{O}_{40}$ supported onmesoporous silica SBA-15. Catal. Lett. 93, 209-212 (2004)

21. Johnson, B.J.S., Stein, A.: Surface modification of mesoporous, macroporous, and amorphous silica with catalytically active polyoxometalate clusters. Inorg. Chem. 40, 801-808 (2001)

22. Kaleta, W., Nowinska, K.: Immobilisation of heteropoly anions in Si-MCM-41 channels by means of chemical bonding to aminosilane groups. Chem. Commun. (6), 535-536 (2001)

23. Bamoharram, F.F.: Role of polyoxometalates as green compounds in recent developments of nanoscience. Synth. React. Inorg., Met. Org., Nano Met. Chem. 41(8), 893-922 (2011)

24. Kozhevnikov, I.V., Sinnema, A., Jansen, R.J.J., Pamin, K., Vanbekkum, H.: New acid catalyst comprising heteropoly acid on a mesoporous molecular-sieve MCM-41. Catal. Lett. 30, 241-252 (1995)

25. Mizuno, N., Misono, M.: Heterogeneous catalysis. Chem. Rev. 98, 199-217 (1998)

26. Papaconstantinou, E.: Photochemistry of polyoxometallates of molybdenum and tungsten and/or vanadium. Chem. Soc. Rev. 18, 1-31 (1989)

27. Hiskia, A., Mylonas, A., Papaconstantinou, E.: Comparison of the photoredox properties of polyoxometallates and semiconducting particles. Chem. Soc. Rev. 30(1), 62-69 (2001)

28. Kozhevnikov, I.V.: Catalysis by heteropoly acids and multicomponent polyoxometalates in liquid-phase reactions. Chem. Rev. 98, 171-198 (1998) 